\title{
GAME ADVENTURE HORROR “LET'S ESCAPE” DENGAN UNITY ENGINE BERBASIS DESKTOP MENGGUNAKAN METODE FINITE STATE MACHINE
}

\author{
Zakiey Cahya Ardi Wahana, Suryo Adi Wibowo, Abdul Wahid \\ Program Studi Teknik Informatika S1, Fakultas Teknologi Industri \\ Institut Teknologi Nasional Malang, Jalan Raya Karanglo km 2 Malang, Indonesia \\ zakieycahya@gmail.com
}

\begin{abstract}
ABSTRAK
Saat ini di tahun 2020 merupakan tahun yang sangat di batasi kegiatan di luar rumah di karenakan pandami COVID19 yang menyerang berbagai negara di dunia, kebanyakan orang melakukan pekerjaan, bermain di rumah yang membuat banyak orang merasa bosan dan banyak orang bermain game sebagai sarana penghilang rasa bosan tersebut. Banyak platform juga device untuk sarana bermain game dan yang sangat digemari adalah game online/offline di PC maupun di Smartphone. Yang menarik dalam game tersebut selalu ada NPC (Non Playable Character) yang membuat game semakin menantang dan menarik. Karena teknologi semakin maju sekarang banyak NPC pada game yang dapat meniru perilaku atau kebiasaan manusia. Dalam hal ini dibutuhkan kecerdasan buatan agar NPC dapat bergerak atau melakukan aksi seperti manusia. Dan FSM ( Finite State Machine) merupakan salah satu metode kecerdasan buatan dalam pembuatan aksi NPC pada game.

Dalam perancangan game ini, penulis memakai beberpa aplikasi berupa Unity $3 D$ dengan bahasa pemrograman C\#, CrazyTalk Animator, CorelDraw X7, dan PhotoShop CS6. Dalam pembuatan game ini menerapkan metode kecerdasan buatan Finite State Machine sebagai metode untuk menentukan aksi musuh kepada player saat jarak aksi tersebut telah terdeteksi.

Hasil pengujian game Lets Escape yang telah dilakukan menunjukan bahwa fungsi yang terdapat pada game dari menu utama hingga level 1, level 2, dan level 3 dapat berhasil. Kontrol pada game berhasil berjalan dengan baik. Metode kecerdasan buatan Finite State Machine yang diaplikasikan kepada musuh juga boss, dapat mendeteksi posisi player dan menghasilkan output yang sesuai berupa menyerang saat bertemu dengan player juga mengejar pada jarak yang di tentukan. Cerita hantu yang ditampilkan $70 \%$ tersampaikan kepada pengguna. Dan karakter yang cukup menarik juga kontroler game yang mudah di mengerti
\end{abstract}

Kata kunci : Game, Unity3D, Finite State Machine, Non Player Character

\section{PENDAHULUAN}

Game merupakan kegiatan atau aktivitas yang selalu kita lakukan dalam kehidupan sehari-hari entah saat bermain bersama teman ataupun belajar di sekolah. Sekarang pun game tidak hanya untuk menghibur diri setelah menjalani kegiatan yang membuat kacau pikiran, bahkan game sekarang bisa dijadikan profesi yang menghasilkan banyak uang. Namun dalam sebuah game pun tidak hanya untuk pelepas penat maupun penghibur diri, beberapa pesan atau pelajaran bisa didapatkan pada sebuah game, seperti bagaimana perjuangan suatu karakter yang selalu gigih dalam menghadapi rintangan atau musuh yang selalu menghadang demi mencapai apa yang dicari dalam game tersebut, melatih cara berfikir dan dapat juga mengasah kereatifitas.

Game yang sangat digemari hingga ini merupakan game - game yang bersifat online dimana para pemain dapat bermain bersama teman yang lain ridak hanya berdua melainkan bisa hingga ratusan orang dan mengejar peringkat agar di akui sebagai player terkuat. Hal ini menyebabkan banyak dari pemain tersebut mengalami stress akibat kalah dan sulit menjadi top player dan kebanyakan pemainnya menjadi terlalu toxic saat bermain game akibat kerap kalah dan rankingnya tak kunjuang naik. Oleh karena itu perlu adanya game offline yang sederhana namun tetap menarik untuk dimainkan.

Game Let's Escape merupakan permainan petualangan dimana pemain akan menjalankan karakter seorang pemuda bernama Leo. Dimana game ini menceritakan tentang seorang Pemuda bernama Leo yang gemar berpetualang dan tersesat di hutan. Ternyata hutan yang dimasuki adalah hutan yang angker disana banyak terdapat hantu-hantu yang jarang diketahui. Leo berusaha mengalahkan juga mencari jalan keluar dari hutan tersebut dan agar bisa kembali ke rumah menceritakan apa yang telah dilihat dan terjadi disana.

Metode yang digunakan dalam game "Let's Escape" menggunakan metode FSM (Finite State Machine), dimana metode tersebut berfungsi untuk pengambilan keputusan pada karakter NPC (Non Playable Character) yaitu karakter yang digerakkan oleh kecerdasan buatan yang digunakan untuk mendukung game tersebut seperti karakter musuh agar gerakan dan aksi dari musuh tanpa melibatkan pengguna game (Adi, dkk, 2009). Dari uraian diatas penulis ingin mengimplementasikan penggunaan metode FSM (Finite State Machine) untuk melakukan pembuatan game dengan judul "Let's Escape" yang merupakan game 2D dengan genre Adventure game, dengan tipe side scroller game menggunakan Unity 
sebagai game engine. Pemilihan metode FSM dikarenakan game ini bergenre side scroller dimana karakter akan sering bertemu juga berinteraksi dengan musuh, dengan mnggunakan metode ini musuh akan terus mengejar dan menyerang yang dapat memberikan kesan action yang seru pada pemain. Mengapa panulis memilih menggunakan FSM dibandingkan dengan metode lain seperti fuzzy di karenakan game ini merupakan game sidecroller sederhana dimana metode FSM lebih mudah diimplementasiakan dibanding metode fuzzy yang dimana harus mencari nilai preferensi atau parameter agar aksi yang di lakukan bisa akurat. Penulis juga ingin memberikan beberapa kisah horror daerah jawa timur pada game tersebut yang dimana Indonesia ini memiliki beragam kisah hantu urban legend yang menarik untuk diceritakan dan diketahui. Pada saat selesai tiap levelnya akan menampilkan cerita / kisah dari hantu yang telah dikalahkan pada level tersebut.

\section{TINJAUAN PUSTAKA}

\subsection{Penelitian Terdahulu}

Penelitian yang Terkait Metode pembuatan AI pada game dengan menggunakan Metode Finite State Machine juga pernah digunakan oleh peneliti terdahulu. Maka peneliti juga perlu untuk mempelajari penelitian-penelitian terdahulu sebagai dasar refrensi dalam pengerjaan penelitian ini.

Rujukan penelitian pertarna yaitu penelitian oleh Tito Bimantoro dan Hanny Haryanto dari Universitas Dian Nuswantoro pada tahun 2016 dengan judul Pemodelan Perilaku Musuh Menggunakan Finite State Machine (FSM) Pada Game Pengenalan Unsur Kirnia. Dalam penelitian tersebut peneliti menggunakan metode, finite state machine pada pemodelan untuk kelakuan pada musuh. Dengan menggunakan metode Finite State Machine musuh akan bereaksi pada karakter utama berdasarkan jarak dari player terhadap musuh.

Rujukan penelitian kedua yaitu penelitian oleh Miftah Fauzan Rahadian, Addy Suyatno, dan Septya Maharani dari Universitas Mulawarman pada tahun 2016 dengan judul PENERAPAN METODE FINITE STATE MACHINE PADA GAME "THE RELATIONS'HIP. Dalam penelitian tersebut peneliti menggunakan metode finite state machine ntuk menentukan respons karakter NPC yang berbeda tergantung dari interaksi yang dilakukan oleh pemain Saat pertama dijalankan NPC akan berada pada State idle, kemudian NPC akan mulai melakukan gerakan dan melakukan interaksi setelah mendapat perintah oleh player.

Rujukan penelitian ketiga yaitu penelitian oleh Silvia Rostianingsih, Hans Kristian Wijaya, Gregorius Satia Budhi dari Universitas Kristen Petra pada tahun 2013 dengan judul PERANCANGAN DAN PEMBUATAN GAME SIMULASI PERTANIAN DAN PETERNAKAN. Peneliti menerapkan metode finite state machine untuk menentukan tanggapan karakter non-player character yang menjadi pemain lain dalam game tersebut. NPC tersebut masuk dalam karakter utama, yang kemudian akan berinteraksi satu sama lain, dan metode Finite State Machine diterapkan pada aktivitas bercocok tanam dari setiap karakter.

Rujukan penelitian ke empat yaitu penelitian yang dilakukan oleh Irawan, J.D, Adi Wibowo S, dkk, 2015 berjudul "Pelatihan Pembuatan Game Menggunakan Greenfoot". Dalam penelitian ini menyebutkan bahwa pembuatan game dengan menggunakan greenfoot merupakan salah satu cara untuk belajar pemrograman mudah dipahami karena hanya memerlukan sedikit perintah yang ditambahkan untuk membuat sebuah game.(Irawan, J.D,Adi Wibowo S, dkk, 2015)

Rujukan penelitian kelima yaitu penelitian yang dilakukan oleh Pratama, 2014 berjudul "Game Adventure Misteri Kotak Pandora" penelitan ini mejelaskan tenang penerapan game adventure berbasis dekstop menggunakan software Unity3D dalam penelitian ini juga menjelaskan tentang berbagai macam genre game yang ada pada saat ini, khusus nya untuk game adventure.(Pratama, 2014)

\subsection{Permainan (Game)}

Game merupakan kegiatan terstruktur atau semi terstruktur yang umumnya bertujuan untuk hiburan dan terkadang dapat digunakan sebagai sarana pendidikan. Karakterisitik game yang menyenangkan, menginspirasi, membuat kecanduan dan kolaboratif membuat aktifitas ini digemari oleh banyak orang (Wahono, R.S. 2009).

\subsection{AI(Artificial Intelligence)}

Kecerdasan buatan atau Artificial Intelligence itu sendiri dimunculkan oleh seorang professor dari Massachusetts Institute of Technology yang bernama John McCarthy pada tahun 1956 pada Darmouth Conference yang diikuti oleh para peneliti AI. Pada konferensi tersebut juga didefinisikan tujuan utama dari kecerdasan buatan, yaitu mengetahui dan memodelkan proses-proses berpikir manusia dan mendesain mesin agar dapat menirukan perbuatan manusia tersebut.(Wijaya, 2013)

\subsection{FSM (Finite State Machine)}

Finite State Machine (FSM) adalah sebuah metodologi perancangan sistem kontrol yang menggambarkan perilaku atau prinsip kerja sistem dengan menggunakan tiga hal berikut: State (Keadaan), Event (kejadian) dan action (aksi). Sebagai sebuah metodologi perancangan sistem kontrol, penerapan FSM telah banyak diimplementasikan pada perangkat lunak, khususnya pada game. (Rahadian, 2016). 


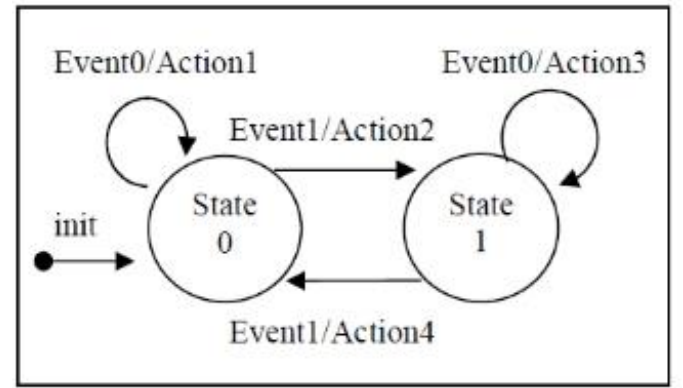

Gambar 2.1 Diagram state sederhana (Sumber :Setiawan, 2006)

Gambar 2.1 memperlihatkan FSM dengan dua buah state dan dua buah input serta empat buah output yang berbeda seperti terlihat pada gambar, ketika sistem mulai dinyalakan, sistem akan berpindah menuju State0, pada keadaan ini sistem akan menghasilkan Action1 jika terjadi masukan Event0, sedangkan jika terjadi Event 1 maka Action 2 akan dieksekusi kemudian sistem selanjutnya berpindah ke keadaan State1 dan seterusnya.

\section{METODE PENELITIAN}

\subsection{DESAIN GAME}

\subsubsection{Alur Cerita}

Jalan cerita dari Game Let's Escape ini menceritakan tentang seorang Pemuda bernama Leo yang gemar berpetualang dan tersesat di daerah yang sangat sepi atau bisa di bilang ke alam lain. Ternyata daerah yang dimasuki adalah dunia ghoib disana banyak terdapat hantu-hantu yang jarang diketahui. Leo berusaha mengalahkan juga mencari jalan keluar dari hutan tersebut dan agar bisa kembali ke rumah menceritakan apa yang telah dilihat dan terjadi disana.

Game ini terbagi menjadi tiga level utama. Masing-masing level memiliki latar, musuh dan tingkat kesulitan yang berbeda-beda. Beberapa aturan dari game ini yaitu :

\section{Desain Level 1}

1. Player memiliki HP (Health Point) dalam bentuk slidebar.

2. Player memiliki aksi utama yaitu, Shoot (menembak), jump, run.

3. Player mati jika HP habis

4. Jika player mati, player mengulang dari level 1.

5. Untuk menyelesaikan permainan ini, user harus melewati semua rintangan level 1 dan mengalahkan Boss level 1. Dan masuk ke dalam rumah

\section{Desain Level 2}

1. Player memiliki HP (Health Point) dalam bentuk bar.

2. Player memiliki aksi utama yaitu, Shoot (menembak), jump, run.

3. Player mati jika HP habis

4. Musuh pada level 2 memiliki animasi dan karakter yang berbeda.

5. Jika player mati, maka mengulang di level 2

6. Untuk menyelesaikan permainan ini, user harus melewati semua rintangan level 2 dan mengalahkan boss level 2. Dan masuk ke dalam rumah.

\section{Desain Level 3}

1. Player memiliki HP (Health Point) dalam bentuk bar.

2. Player memiliki aksi utama yaitu, Shoot (menembak), jump, run.

3. Player mati jika HP habis

4. Jika player mati, player mengulang dari level 3.

5. Untuk menyelesaikan permainan ini, user harus melewati semua rintangan level 3 dan melawan boss level 3.dan masuk ke dalam rumah.

6. Karakter bos pada game ini mempunyai ukuran dan health yang lebih besar dari Enemy lainnya.

\subsubsection{Perancangan FSM pada Musuh}

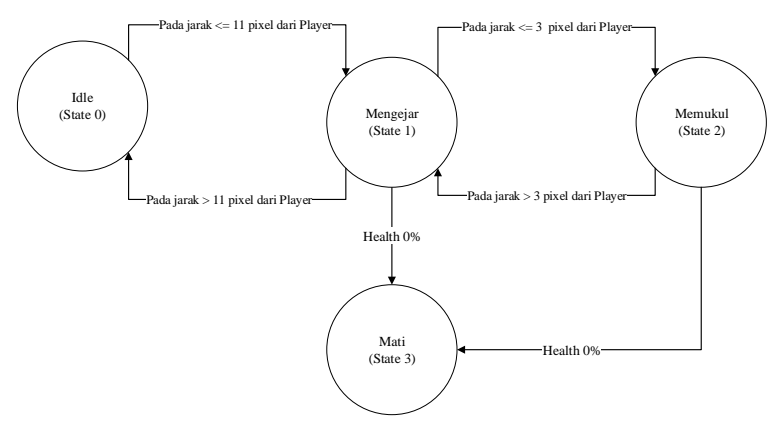

Gambar 3.1 Perancangan Diagram FSM Hantu

Alur Finite State Machine disini menjelaskan ketika sistem dijalankan maka sistem mula-mula berada pada state 0 (Bergerak atau patroli), jika player pada jangankauan enemy (jarak $\leq 11$ pixel) maka state 1 (Mengejar) akan dijalankan dan ketika player berada pada jarak (>11 pixel) maka musuh akan kembali pada state 0. Jika berada pada jangkauan musuh, player (jarak $\leq 3$ pixel) maka state 2 (Memukul) dan ketika player berada pada jarak ( $>3$ pixel) maka musuh akan kembali pada state 1 atau kembali mengejar dan ketika health bar enemy mencapai $0 \%$ maka state 3 (Mati) akan dijalankan. 


\subsubsection{Flowchart Sistem Game}

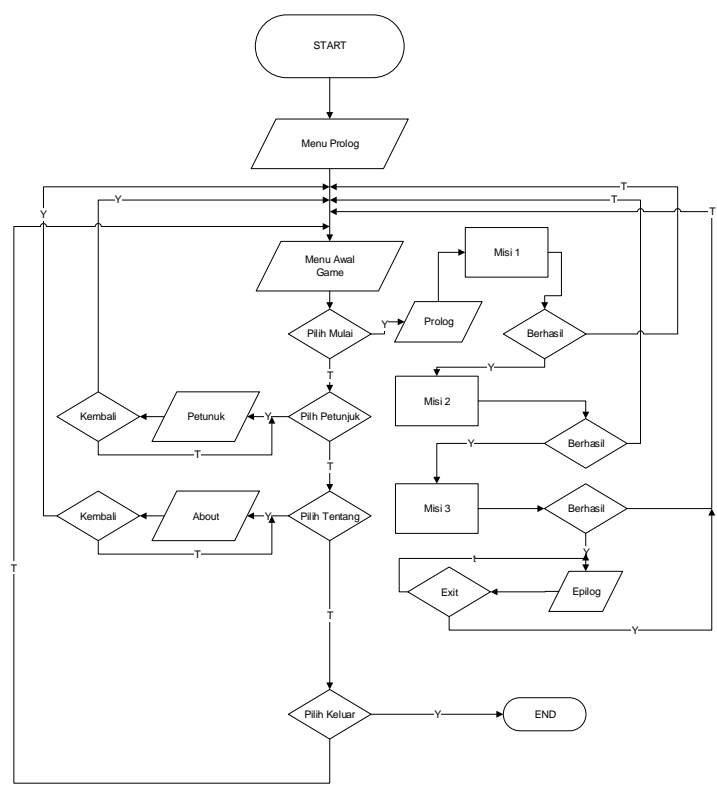

Gambar 3.2 Flowchart Sistem Game

Flowchart game menjelaskan alur dari game yang dikembangkan,pada game play jika pemain ingin bermain harus menang level 1 agar bisa bermain pada level selanjutnya. Jika pemain gagal menyelesaikan misi pada level 2, dan 3 maka dinyatakan game over dan kembali ke menu utama.

\subsubsection{STRUKTUR MENU}

Struktur Menu Pada Game Lets Escape

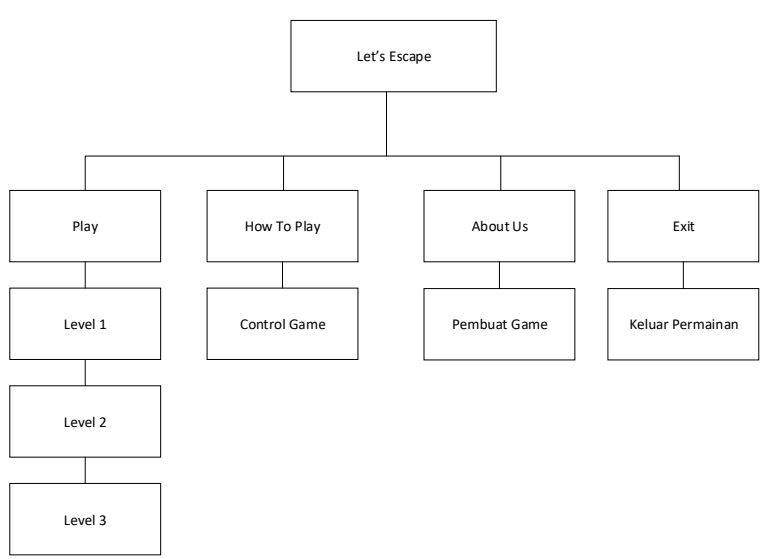

\subsubsection{STORYBOARD}

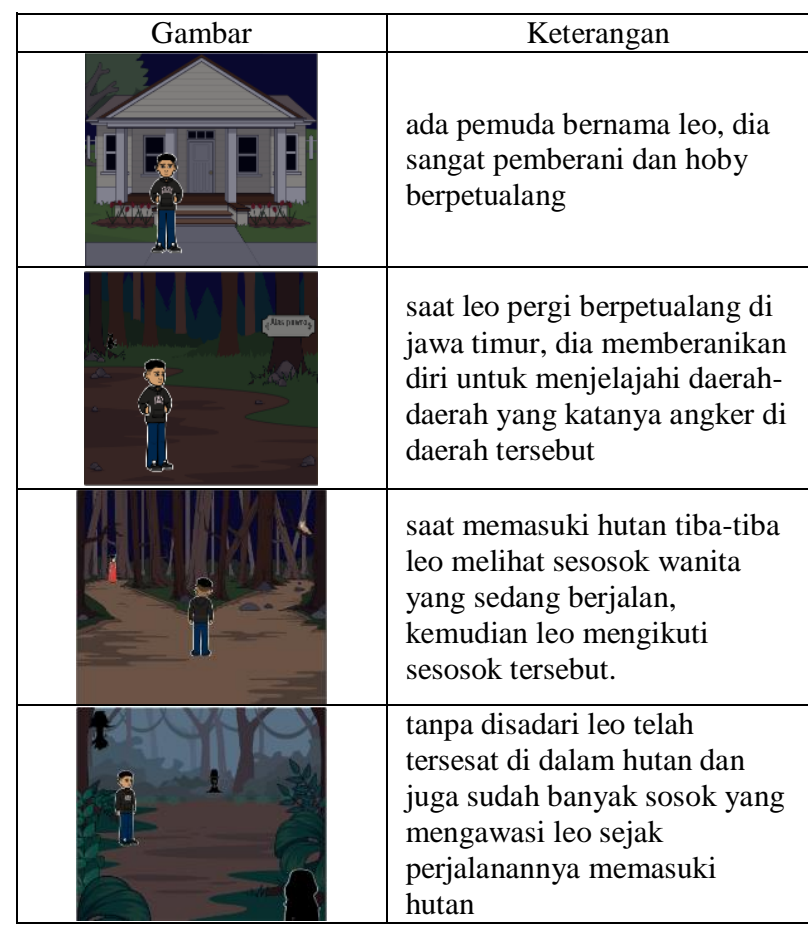

\subsubsection{DESAIN CHARACTER}

Tabel Rancangan Desain karakter

\begin{tabular}{|c|c|c|}
\hline No. & Karakter & Keterangan \\
\hline 1 & & $\begin{array}{c}\text { LEO } \\
\text { Serangan : } 10 \\
\text { Kecepatan : } 10 \\
\text { HP(Health Point }): 100\end{array}$ \\
\hline 2 & 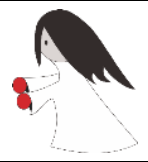 & $\begin{array}{c}\text { KUNTI } \\
\text { Serangan }: 8 \\
\text { Kecepatan }: 15 \\
\text { HP(Health Point }): 60\end{array}$ \\
\hline 3 & & $\begin{array}{c}\text { POCONG } \\
\text { Serangan }: 7 \\
\text { Kecepatan }: 10 \\
\text { HP(Health Point }): 50\end{array}$ \\
\hline 4 & & $\begin{array}{c}\text { BUTO } \\
\text { Serangan : } 15 \\
\text { Kecepatan : } 5 \\
\text { HP(Health Point }): 70\end{array}$ \\
\hline
\end{tabular}

Gambar 3.3 Struktur menu 


\subsubsection{ENVIRONMENT GAME}

\begin{tabular}{|c|c|c|}
\hline No. & Environment & Keterangan \\
\hline 1 & & Lantai yang melayang \\
\hline 2 & & Rumah tempat finish \\
\hline 3 & & \\
\hline 4 & & Lepohonan dalam game \\
\hline 5 & & Gedung dalam game \\
\hline 6 & & Jebakan pada game \\
\hline
\end{tabular}

\section{HASIL DAN PEMBAHASAN}

4.1 Penerapan script pada player dan karakter. penerapan script pada player bertujuan agar player dapat di kontrol oleh pemain. Kontrol pada player dapat berupa bergerak, melompat, menembak, dan sebagainya.

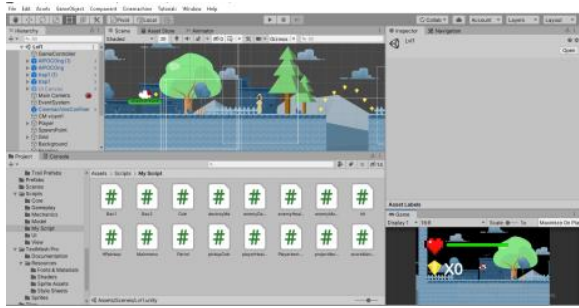

Gambar 4.1 Implentasi Player dan karakter enemy

Pada gambar 4.1 merupakan pengimplementasian script pada player dan karakter enemy,ditambahkan karakter ke dalam unity 2019.3.11f1 dan ditambahkan script agar bisa bergerak sesuai yang diingikan oleh pengembang.

\subsection{2 AI pada musuh}

AI pada musuh merupakan agar musuh dapat bereaksi ketika ada aksi dari player. Misal player berada pada jarak tertentu maka aksi dari musuh bisa berupa mengejar, menyerang dan sebagainya sesuai aksi yang telah di terapkan pada musuh. Untuk implementasi musuh dapat di lihat pada Gambar 4.2 .

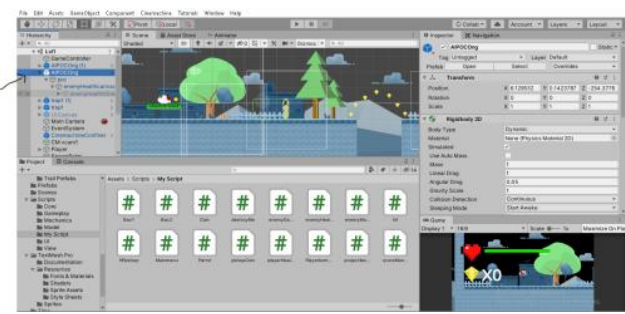

Gambar 4.2 AI pada Musuh

\subsection{Tampilan Menu Utama}

Tampilan menu utama adalah tampilan awal yang akan muncul pada saat pemain menjalankan Game "LETS ESCAPE". Pada tampilan awal ini berisikan tombol Play, how to play, about, Exit. Play untuk memulai game baru, tombol How to play berisi cara controller player, tombol About berisikan tentang creator game dan tombol exit untuk keluar dari game. Tampilan menu utama seperti Gambar 4.3.

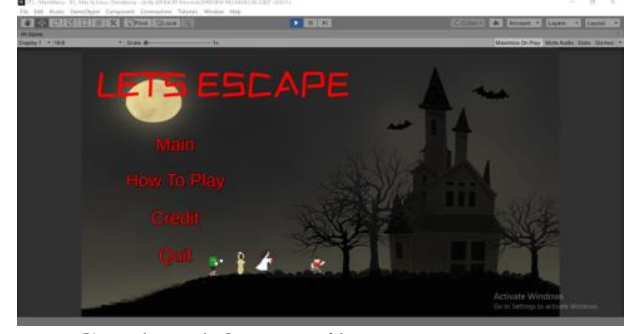

Gambar 4.3 Tampilan Menu Utama

\subsection{Tampilan How To Play}

Tampilan How To Play adalah menu untuk mengetahui fungsi tombol yang akan digunakan pada Game "LETS ESCAPE", tampilan dari menu How To Play seperti pada gambar 4.4

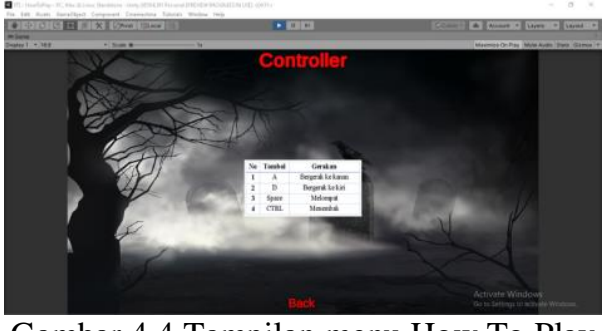

Gambar 4.4 Tampilan menu How To Play

\subsection{Tampilan Menu Credit}

Tampilan теnи Credit adalah tampilan menu untuk mengetahui profil pembuat Game "LETS ESCAPE", tampilan dari menu About seperti Gambar 4.5

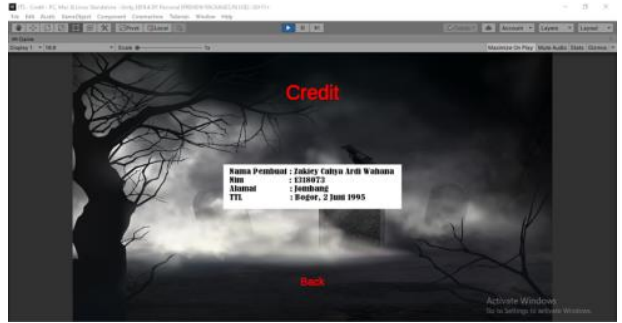

Gambar 4.5 Tampilan menu About

\subsection{Tampilan Menu Level dan Prolog game}

Tampilan Menu Level dan Prolog game adalah tampilan yang menjelaskan alur cerita pada game dan level yang tersedia. Tampilan prolog pada level 1 dapat dilihat pada gambar 4.6 


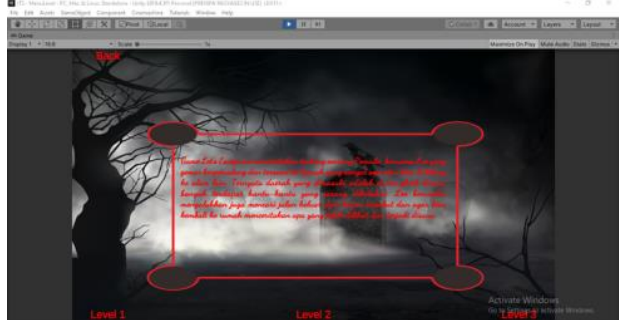

Gambar 4.6 Tampilan Menu Level dan Prolog game

\subsection{Tampilan Gameplay}

Tampilan gameplay pada setiap level yang menampilkan permainan petualangan aksi dengan menghadapi musuh-musuh dan melawan enemy untuk ke level selanjutnya. Tampilan gameplay pada level 1 dapat di lihat seperti pada Gambar 4.7

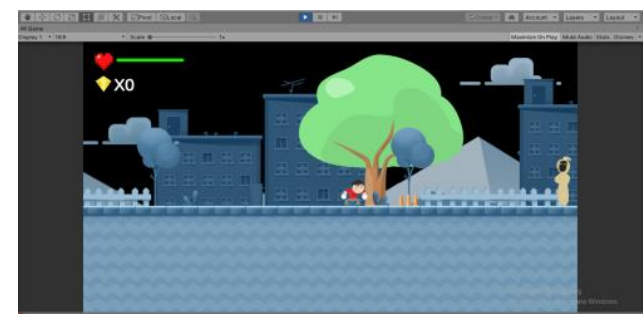

Gambar 4.7 Tampilan Gameplay Level 1

Tampilan gameplay level 2 yang mempunyai latar belakang tanah yang berbeda dengan level 1 dapat dilihat seperti pada gambar 4.8

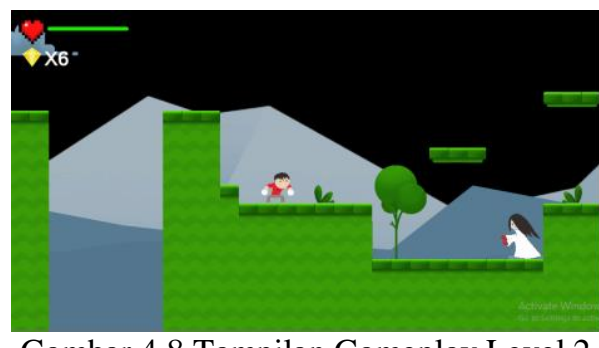

Gambar 4.8 Tampilan Gameplay Level 2

Tampilan gameplay level 3 yang mempunyai latar belakang tanah lebih gelap yang dapat dilihat seperti pada gambar 4.9

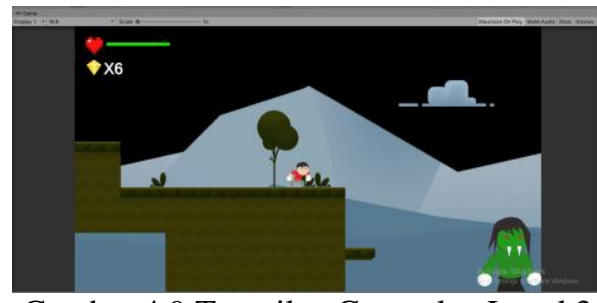

Gambar 4.9 Tampilan Gameplay Level 3

\subsection{Pengujian AI (Artificial Intelligence)}

Pengujian artificial intelligence adalah pengujian mengenai fungsi yang berkaitan dengan artificial intelligence yang ada pada Game "LETS ESCAPE". Hasil pengujian dari artificial intelligence pada game ini seperti pada table 4.1
Table 4.1 Pengujian Artificial Intelligency

\begin{tabular}{|c|c|c|c|c|}
\hline No & Status & Event & Action & Hasil \\
\hline 1 & Idle & $\begin{array}{l}\text { Jika player tidak } \\
\text { menjagkau sight } \\
\text { karakter enemy }\end{array}$ & $\begin{array}{c}\text { Maka enemy } \\
\text { pada posisi } \\
\text { diam }\end{array}$ & Sesuai \\
\hline 2 & Idle & $\begin{array}{c}\text { Jika player tidak } \\
\text { menjangkau } \\
\text { enemy dengan } \\
\text { jangka waktu } 5 \\
\text { detik }\end{array}$ & $\begin{array}{c}\text { Maka } \\
\text { enemy pada } \\
\text { posisi } \\
\text { melihat } \\
\text { kanan dan } \\
\text { kiri } \\
\end{array}$ & Sesuai \\
\hline 3 & Idle & $\begin{array}{c}\text { Jika player } \\
\text { menjangkau } \\
\text { sight enemy } \\
\text { dengan jarak } 11 \\
\text { pixel }\end{array}$ & $\begin{array}{c}\text { Maka enemy } \\
\text { akan } \\
\text { mengejar }\end{array}$ & Sesuai \\
\hline 4 & Idle & $\begin{array}{c}\text { Jika player } \\
\text { menjangkau } \\
\text { sight enemy } \\
\text { dengan jarak } 3 \\
\text { pixel }\end{array}$ & $\begin{array}{c}\text { Maka } \\
\text { enemy akan } \\
\text { menyerang }\end{array}$ & Sesuai \\
\hline 5 & Idle & $\begin{array}{c}\text { Jika player } \\
\text { berjarak lebih } \\
\text { dari }>11 \text { pixel } \\
\text { dari enemy }\end{array}$ & $\begin{array}{c}\text { Maka } \\
\text { enemy akan } \\
\text { pada posisi } \\
\text { idle }\end{array}$ & Sesuai \\
\hline
\end{tabular}

Hasil pengujian AI di setiap level pada game "LETS ESCAPE" akan di tampilkan sebagai berikut:

\section{Musuh Pada game}

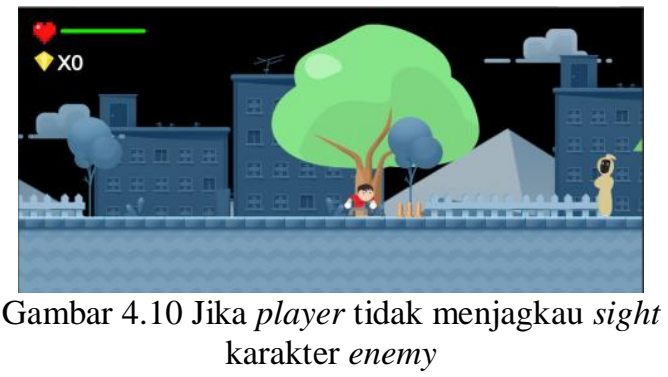

Pada gambar 4.10 di perlihatkan jika player tidak menjangkau sight musuh maka musuh akan tetap pada keadaan idle.

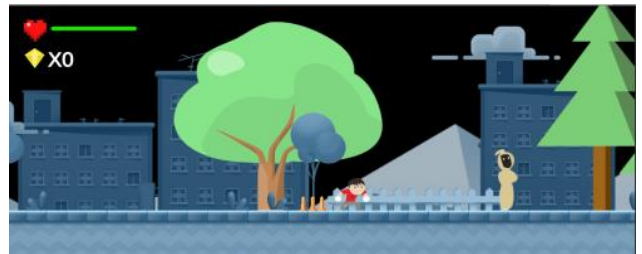

Gambar 4.11 Jika player tidak menjangkau musuh dengan jangka waktu 5 detik

Pada gambar 4.11 di perlihatkan jika player tidak menjangkau musuh dengan jangka waktu 5 detik maka musuh akan tetap pada keadaan idle dan akan berbalik arah kiri dan kanan. 


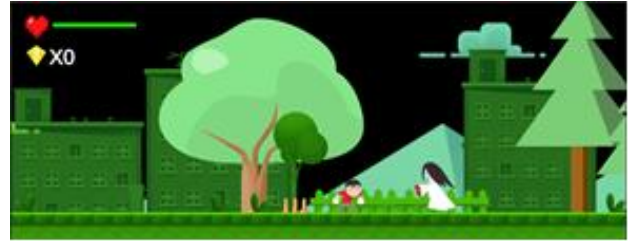

Gambar 4.12 Jika player menjangkau sight musuh dengan jarak 11 pixel

Pada gambar 4.12 di perlihatkan jika player menjangkau sight musuh dengan jarak 11 pixel maka musuh akan mengejar player.

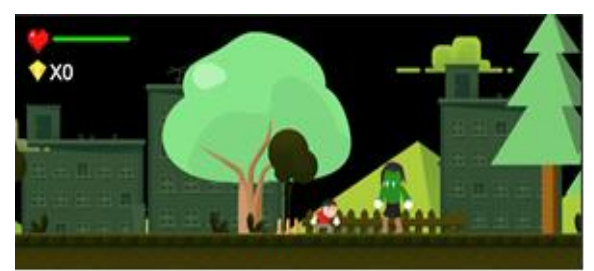

Gambar 4.13 Jika player menjangkau sight musuh dengan jarak 3 pixel

Pada gambar 4.13 di perlihatkan jika player menjangkau sight musuh dengan jarak 3 pixel maka musuh akan memberikan damage pada player, di tandai dengan berkurangnya hp bar player.

\section{Jebakan pada game}

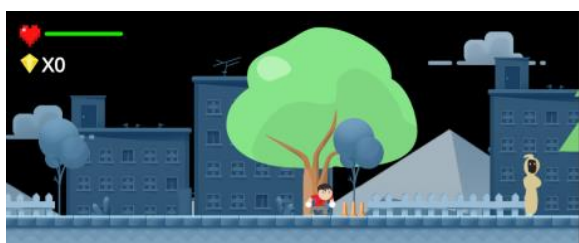

Gambar 4.22 jika player tidak menyentuh jebakan

Pada gambar 4.22 diperlihatkan jika player tidak menyentuh jebakan maka player tidak akan terkena damage.

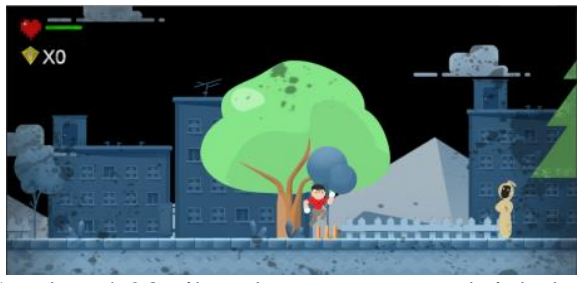

Gambar 4.23 Jika player menyentuh jebakan

Pada gambar 4.23 diperlihatkan jika player menyentuh jebakan maka player akan telempar ke udara dan menerima damage dan berkurang jumlah hp.

\subsection{Pengujian Funsional}

Pengujian fungsioanal adalah pengujian mengenai proses fungsioanal yang terjadi dalam game. hasil pengujian dapat dilihat pada tabel 4.2
Tabel 4.2 Pengujian Fungsional

\begin{tabular}{|c|c|c|c|}
\hline \multirow{2}{*}{ No } & \multirow{2}{*}{ Item Uji } & \multicolumn{2}{|c|}{ Hasil } \\
\hline & & Berhasil & Gagal \\
\hline 1 & Menu Utama & $\sqrt{ }$ & \\
\hline 2 & Button Main & $\sqrt{ }$ & \\
\hline 3 & Button How To Play & $\sqrt{ }$ & \\
\hline 4 & Button Credit & $\sqrt{ }$ & \\
\hline 5 & Buton Quit & $\sqrt{ }$ & \\
\hline 6 & Level 1 game & $\sqrt{ }$ & - \\
\hline 7 & Level 2 game & $\sqrt{ }$ & - \\
\hline 8 & Level 3 game & $\sqrt{ }$ & - \\
\hline 9 & Bar Health poin Player & $\sqrt{ }$ & - \\
\hline 10 & Bar Health poin Musuh & $\sqrt{ }$ & - \\
\hline 11 & Animasi pada Game & $\sqrt{ }$ & - \\
\hline 12 & $\begin{array}{l}\text { Hp musuh berkurang ketika } \\
\text { terkena seranagan }\end{array}$ & $\sqrt{ }$ & - \\
\hline 13 & $\begin{array}{l}\text { Hp player berkurang ketika } \\
\text { terkena serangan }\end{array}$ & $\sqrt{ }$ & - \\
\hline 14 & Pengambilan penambah HP & $\sqrt{ }$ & \\
\hline 15 & Pengambilan koin & $\sqrt{ }$ & \\
\hline 16 & $\begin{array}{l}\text { Pengujian partikel } \\
\text { tembakan }\end{array}$ & $\sqrt{ }$ & \\
\hline 17 & $\begin{array}{l}\text { Musuh meyerang pada jarak } \\
\text { tertentu }\end{array}$ & $\sqrt{ }$ & - \\
\hline 18 & $\begin{array}{l}\text { Musuh berjaga pada jarak } \\
\text { tertentu }\end{array}$ & $\sqrt{ }$ & \\
\hline 19 & $\begin{array}{l}\text { Game tamat ketika HP } \\
\text { player } 0 \%\end{array}$ & $\sqrt{ }$ & - \\
\hline 20 & Backsound & $\sqrt{ }$ & \\
\hline
\end{tabular}

\subsection{Pengujian kontrol}

Pengujian kontrol player adalah pengujian kegunaan dari tombol yang sudah diterapkan untuk menggerakan main character. Hasil pengujian player pada table 4.3

Table 4.3 Pengujian Control

\begin{tabular}{|c|c|l|c|}
\hline No & Tombol & \multicolumn{1}{|c|}{ Action } & Hasil \\
\hline 1. & A & Karakter bergerak ke Kiri & Sesuai \\
\hline 2. & D & Karakter bergerak kanan & Sesuai \\
\hline 3. & Spasi & Lompat & Sesuai \\
\hline 4. & CTRL & Karakter Menembak & Sesuai \\
\hline
\end{tabular}

Dari tabel 4.3 ketika pemain menekan tombol huruf A, D, Spasi, dan CTRL bergerak sesuai dengan fungsinya.Huruf A untuk bergerak ke arah kiri, huruf $\mathrm{D}$ untuk bergarak ke arah kanan, space untuk melompat,. Dan untuk melakukan serangan menggunakan tombol CTRL. Dari penjelasan diatas menunjukan bahwa semua fungsi dari kontrol berjalan sesuai dengan fungsinya dengan tingkat keberhasilan mencapai $100 \%$.

\subsection{Pengujian karakter utama.}

Pengujian karakter utaman disini di dasarkan pada apa saja yang bisa di lakukan karakter utama di dalam 
game seperti berjalan, playercontroler, dan lain-lain. Agar lebih jelas dapat di jelaskan pada Tabel 2 di bawah ini.

Tabel 2 Pengujian Charakter

\begin{tabular}{|c|l|c|c|}
\hline No & \multicolumn{1}{|c|}{ Yang Di Ujikan } & Berfungsi & Tidak \\
\hline 1. & $\begin{array}{l}\text { Control Charakter } \\
\text { menggunakan Keyboard }\end{array}$ & YA & - \\
\hline 2. & $\begin{array}{l}\text { Damage Obstacle pada } \\
\text { player }\end{array}$ & YA & - \\
\hline 3. & $\begin{array}{l}\text { Damage Player pada } \\
\text { Enemy }\end{array}$ & YA & - \\
\hline 4. & Healbar Player & YA & - \\
\hline
\end{tabular}

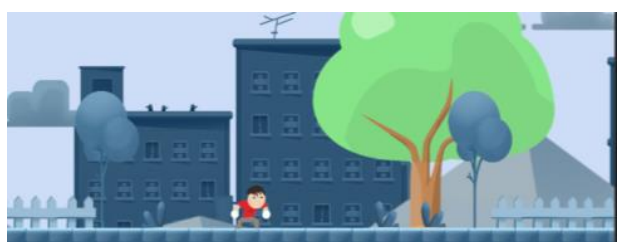

Gambar 4.24 implementasi charakter controller(karakter di possisi awal).

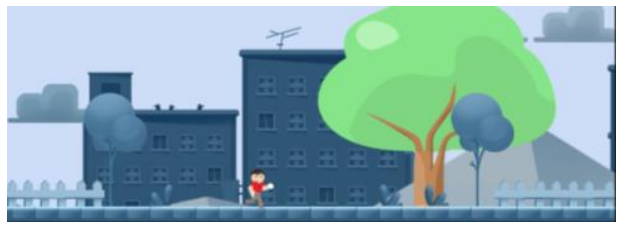

Gambar 4.25 Implementasi character controller(karakter berlari).

Gambar 4.24 dan gambar 4.25 menunjukkan dimana jika menekan tombol D chrakter akan berjalan kearah kanan. Selain itu karakter juga dapat berlari kea rah sebaliknya dengan menekan tombol A sesuai harapan penulis.

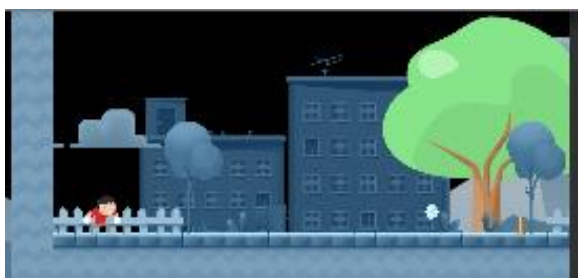

Gambar 4.26 player menembak

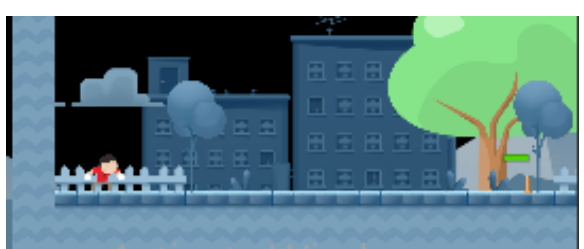

Gambar 4.27 Implemetasi Damage Player to Enemy.

Didalam gambar 4.26 dan 4.27 di gambarkan bahwa jika player menembakkan Projectile dan menyentuh enemy maka enemy akan berkurang HPnya sesuai pada gambar.

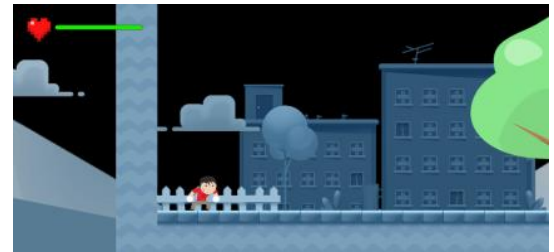

Gambar 4.28 Implemetasi Player Healbar (HP Penuh)

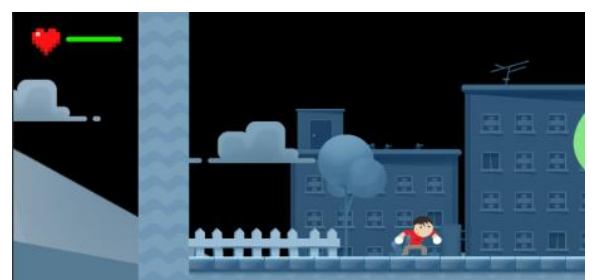

Gambar 4.29 Implementasi Player Healbar berkurang.

Didalam Gambar 4.28 dan Gambar 4.29 dapat dilihat dimana di saat enemy dan obstacle menyentuh player maka healBar akan berkurang sebnyak 10 point.

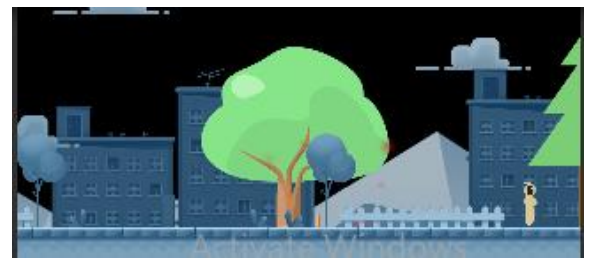

Gambar 4.30 Implementasi Player Mati jika Healbar habis.

Didalam Gambar 4.30 dapat di lihat player hilang dari layar di karenakan player mati akibat healthbar habis.

\subsection{Pengujian User}

Pengujian User atau kuisioner dilakukan untuk mengetahui kepuasan pengguna dalam memainkan game "LETS ESCAPE" dan tanggapan terhadap isi di dalam game. Pengujian di lakukan oleh 10 orang siswa dan siswi. Hasil dari pengujian dapat di lihat pada tabel 4.4

\begin{tabular}{|c|l|c|c|c|}
\hline \multirow{2}{*}{ No } & \multirow{2}{*}{ Pertanyaan } & \multicolumn{3}{|c|}{ Tanggapan pengguna } \\
\cline { 3 - 5 } & & Baik & Cukup & Kurang \\
\hline 1 & Control pada game & 8 & 2 & \\
\hline 2 & Desain karakter game & 5 & 4 & 1 \\
\hline 3 & Game sudah menarik & 5 & 4 & 1 \\
\hline 4 & $\begin{array}{l}\text { Informasi game } \\
\text { (cerita game) }\end{array}$ & 7 & 3 & \\
\hline 5 & Musuh dapat bergerak & 8 & 2 & \\
\hline & Jumlah & 33 & 15 & 2 \\
\hline
\end{tabular}




\section{KESIMPULAN DAN SARAN}

\subsection{Kesimpulan}

Setelah pembuatan Game Let's Escape, maka penulis dapat mengambil kesimpulan :

1. Implementasi kecerdasan buatan FSM (Finite State Machine) berhasil diterapkan pada game Let's Escape dengan aksi musuh dapat mengejar dan menyerang player dengan kondisi tertentu.

2. Semua aksi pada player berhasil diimplementasikan sesuai dengan yang diharapkan.

3. Fungsi yang diterapkan pada karakter game pada level 1,2, 3 berhasil berjalan.

4. Alur game yang berjalan dari level 1 hingga level 3 berjalan sesuai harapan.

5. Controller yang digunakan sudah bekerja dengan baik.

6. Cerita hantu yang ditampilkan tersampaikan ke pengguna.

7. Cotroller yang di gunakan nyaman untuk di gunakan.

8. Tampilan karakter $50 \%$ menarik, $40 \%$ cukup dan $10 \%$ tidak menarik.

\subsection{Saran}

Setelah dilakukan pengujian terhadap Game Let's Escape dan masih terdapat kekurangan maka dari itu disarankan :

1. Dapat dikembangkan sebagai mobile game berbasis platform android dan ios agar dapat diupload pada app store masing-masing platform sehingga dapat menambah nilai ekonomi pada game.

2. Dapat ditambah jumlah Level dan di tingkatkan kualitas grafiknya.

3. Dapat ditambahkan item-item yang lebih banyak.

4. Dapat ditambahkan lebih banyak cerita hantu dari Indonesia.

\section{DAFTAR PUSTAKA}

[1] Bimantoro, 1. dan Haryanto, H. 2016. Pemodelan Perilaku Musuh Menggunakan Finite State machine(FSM) Pada Game Pengenalan Unsur Kimia. Semarang. Universitas Dian Nuswantoro

[2] Rahadian, M.F. et al. 2016. Penerapan metode finite state machine pada game "the relationship". Samarinda. Universitas Mulawarman

[3] Rostianingsih, S. et al. 2013. Game simulasi finite state machine untuk pertanian dan peternakan. Surabaya. Universitas Kristen Petra

[4] Tanjung, M.A.P. 2012. Analisis Pengaruh Storytelling Terhadap Game Lorong Waktu Pangeran Dipenogoro Sebagai Media Edukasi Sejarah

[5] http://elib.unikom.ac.id/files/disk1/648/jbptuni kompp-gdl-mahardikaa-32391- 11-20.unikoa.pdf diak.ses tanggal 15 Maret 2017

[6] Tim Wahana Komputer. 2014. Mudah mernbuat game 3 dimensi menggunakan Unity 3D. Yogyakarta_ Penerbit Andi 